\title{
Interpersonal competencies define effective conservation leadership
}

\section{$\underline{\text { Abstract }}$}

Effective leadership is considered essential for conservation success, but there is currently not enough understanding of what conservation leaders are doing, and what they should be doing, in order to be effective. Other sectors, such as health, commerce, education, industry and the military have studied leadership for decades, and have a good knowledge of particular styles and suitable instruments for measuring leadership effectiveness. This study uses the perspectives of conservation professionals through interviews, a focus group and an online survey, to help develop a more comprehensive picture of the role of leaders, and leadership, within the discipline. The study concludes that competencies that relate to interpersonal leadership skills are key for effectiveness, particularly building trust amongst followers. However, leaders in conservation are not showing these to the same extent as they are showing more technical skills. Future conservation training schemes should incorporate these competencies to ensure leaders are effective. Greater understanding can help inform conservation professionals who wish to invest in leadership development schemes to improve effectiveness across conservation initiatives.

\section{$\underline{\text { Keywords }}$}

conservation psychology; effectiveness; leaders; organisational learning; social skills; training

\section{Introduction}

Conservation 'initiatives' (projects, programmes or organisations) typically require collective action to achieve their goals (Lauber et al. 2011) but such collaboration can be difficult to secure. The complexity of the contexts in which most conservation initiatives operate, notably disparate values of stakeholders, creates management challenges that may compromise overall effectiveness (Black et al. 2011). Navigating this complexity both within and beyond conservation initiatives requires direction in the form of strong leadership (Manolis et al. 2009; Black et al. 2011; CMP 2013). 
Leadership has been identified as "the most important attribute in the toolkit of a conservation biologist" (Deitz et al. 2004). However, little is written about leadership in the conservation literature, though the literature on leadership beyond the conservation sector is better developed; the result of a greater emphasis being placed on identifying core competencies essential to the effective performance of individuals and organisations (Schriescheim \& Neider 1996; Nettles \& Herrington 2007; Curtis et al. 2011). Leadership has been described as "a catalyst without which other good things are quite unlikely to happen" (Leithwood et al. 2008). It has been noted that, across American businesses in 2014, for example, $35 \%$ of training funds was spent on developing leaders at all levels. Effective leadership is a high priority for businesses (Bersin 2014).

Substantial research investments have been made across a diverse range of sectors to identify key leadership competencies and qualities, including healthcare, commerce, politics and education (Bass \& Avolio 1993; Bennis 1999; Kouzes \& Posner 2006). Competencies related to establishing and building personal relationships are considered most important, both within teams and initiatives, and more broadly with stakeholders (Azim et al. 2010; Awan et al. 2015). Effective leaders are inspirational, gain support from followers, and encourage them to work for the good of their group (Bass 1985). These 'interpersonal' leadership competencies promote structured thinking and are essential for solving complex people management problems (e.g., conflict resolution) as opposed to comparatively technical challenges (e.g., population viability analysis) (Schön 1983; Senge 1994; Checkland 2000; Bonar 2007). Other competencies of strong leaders identified in other sectors include conducting effective debriefs (Catalano et al. 2018), providing useful feedback (McCallum et al. 2009), manage resources efficiently (Mumford et al. 2000) and ensure diplomacy (London 1999). Leaders fundamentally determine levels of trust within teams (Burke et al. 2007). Many of these same competencies have been identified in the conservation leadership literature, however, 
considerably less work has gone into assessing the state of leadership in the field and identifying key competencies needed for success.

Research has attempted to define conservation leadership, but many qualities and competencies remain unclear (Bruyere 2015. Here, we define 'leadership competencies' as skills, behaviours, attitudes and judgements that are required to guide individuals or groups towards a common goal. The term 'qualities' we apply more generally to refer to inherent characteristics that may be beneficial, neutral or counter-productive to effective leadership (Black et al. 2011). Previous examinations of conservation leadership literature reviewed citations on Web of Science using the search terms "(conservation biology OR conservation science) AND leadership". A decade ago Manolis et al. (2009) identified 29 articles, a body of work which has grown to 61 articles in a more recent review (Bruyere 2015). Ten repeatedly arising themes within leadership are identified across this body of work which specifically include 1) collaboration and stakeholders (Bengston and Fan 1999; Knight 2006; Ardoin et al. 2015; Macura et al. 2016), 2) direction and motivation of others (Knight et al. 2011; Case et al. 2015; Evans et al. 2015; Bennett et al. 2017), 3) decision making and empowerment (Clark et al. 1994; Cannon et al. 1996; Bengston and Fan 1999; Sjölander-Lindqviste et al. 2015; Bianco et al. 2016), 4) team culture (Westrum 1994; Schwartz 2006; Black et al. 2011; Cheruvelil et al. 2014), 5) public outreach and culturally relevant community engagement (Bodin and Croner 2008; Mattson et al. 2011; Gutiérrez et al. 2011; Sutton 2015; Straka et al. 2018), 6) vision (Black et al. 2011; Mattson et al. 2011; Bruyere 2015; Straka et al. 2018), 7) adaptive management and hands-on leadership (Manolis et al. 2009; Black et al. 2011; Haubold 2012; Cundill et al. 2012; Bruyere 2015), 8) sense of the bigger picture (Black et al. 2011; Black \& Copsey 2014a), 9) networks and relationships (Dietz et al. 2004; Manolis et al. 2009; Ardoin et al. 2015; Imperial et al. 2016), and 10) valuing knowledge including experience, traditions, science and learning (Black et al. 2013; Sjölander-Lindqvist et al. 2015; Catalano et al. 2018). 
Trust, in particular, is widely recognised as essential when establishing conservation initiatives, especially regarding stakeholder relationships (e.g. Redford \& Taber 2000; Knight 2006; Macura et al. 2016). Black et al. (2011) identified the importance of trust in this regard, and suggest a Systems Thinking Leader may be effective within conservation, which the findings of this study support. A Systems Thinking Leader emphasises programme purpose, species and ecosystem needs, integrates management of task, team and individual processes, uses available knowledge and encourages learning, and differentiates one-off phenomena from underlying systemic issues and responds accordingly (Black 2018). As with building trust, strong interpersonal leadership skills are required to build an inspirational vision in any team (Burke et al. 2007).

In short, strong interpersonal skills in leaders are beneficial to conservation initiatives (Ardoin et al. 2015), which mirrors research from other sectors (Black 2015a; Franken et al. 2016). Leadership competencies identified in other disciplines may apply to conservation, although the complexity, uncertainty and limited resources associated with conservation activities, may pose particular challenges less commonly encountered in other sectors (Gordon \& Berry 2006). The competencies defining effective leaders in conservation require greater investigation and testing. Much of the previous literature comprises reviews, or assumes effective competencies can be retrospectively assigned to conservation success stories. However, leadership is a dynamic process, and effective leadership is defined partly by the views of followers (Evans et al. 2015). In this study, we investigate effective leadership competencies and qualities, as perceived by followers, and do not relate this to whether a conservation initiative was 'successful' or not, as these perceptions are both context specific and derived from personal perceptions.

Identifying the essential competencies of strong leaders from the perspective of followers allows future training to be more effectively designed and implemented (Black \& Copsey 2014b). This guides initiatives towards more effective allocation of limited resources, including towards the 
development of their staff, and ultimately increasing the effectiveness and sustainability of their conservation initiatives.

This study aimed to: 1) highlight the fundamental importance of effective leadership and particular aspects informed by leadership studies both within and outside of conservation; 2) reference a baseline framework of leadership competencies against existing trends both within and outside of conservation, that offers direction for future research; and 3) identify topics which inform the development and implementation of content in curricula for undergraduate and postgraduate education and training.

\section{Methods}

\subsection{Defining Leaders and Leadership}

Initially, leaders were defined as those responsible for supervising a team of at least one other individual. However, throughout the study, we recognised that, in practice, the role of an individual is not the sole determinant of an ability to display leadership. Leadership can be practised by any individual (Heifetz 1994) who inspires and mobilises change within, or by, others (Manolis et al. 2009). Participants in the study were therefore able to discuss any colleague they felt was an effective leader, regardless of their formal management responsibilities.

\subsection{Scoping of Potential Themes}

A focus group comprising five professionals (three female, two male) from four international conservation organisations was conducted in June 2016 in Cambridge, United Kingdom to identify leadership competencies. The focus group was facilitated by the lead author and lasted an hour. Semi-structured interviews were also conducted by the lead author in June and July 2016 with nine different conservation professionals (eight male, one female) from eight international organisations. 
Interviews were held both through Skype and in person and lasted between 20 and 36 minutes, with an average of 28 minutes.

Participants were recruited through email invitations, with a set date and location for the focus group to be held. Although participant numbers in this scoping study was limited, in order to ensure as much representativeness of the conservation community as possible, those selected were involved in diverse types of initiatives (e.g. both species and ecosystem focused projects) and represented different international conservation organisations across initiatives from multiple countries. Organisations were chosen initially through the knowledge of the authors, as well as through relevant internet searches. Organisations included members of a well-established multiinstitutional international conservation partnership of agencies and NGOs based in the United Kingdom, to ensure interviews and the focus group could be held in person by the lead author. Interviewees were then selected by searching the websites of organisations, or through recommendations from other conservation professionals. Although most participants had experience in leading teams and conservation initiatives, it was not a prerequisite for participation. This was to encourage discussions about experiences of leadership from both the perspectives of leaders and followers. For both the focus group and the semi-structured interviews, questions were open-ended to encourage all aspects of leadership to emerge naturally amongst participants (Newing 2010a). Question topics included the role of leadership, ideal leadership competencies, qualities and personal experiences, whilst poor leadership was addressed to a lesser extent. Participants were asked to focus on what they perceived to be trainable competencies, but all qualities that emerged were noted. All participants possessed a level of English sufficient to comprehend an information sheet, consent form and interview questions. 


\subsection{Analysis of Scoping Activities}

The focus group and interviews were audio recorded, producing transcripts that were then inductively analysed, through an open coding approach by the lead author, to identify themes of leadership competencies and qualities. Each theme was coded according to terminology used in existing leadership literature, both within conservation and in other disciplines, to enable comparisons across different sectors. A second researcher assessed the coding accuracy and precision for a random sample of $10 \%$ of the content of each transcript (Tversky \& Kahneman 1986). Given the small number of codes, $10 \%$ was deemed appropriate, although no standard exists for defining the proportion of content to be recoded for calculating agreement rates (Reichert et al. 1999). A 70\% level of agreement in codes identified by the two researchers in this sub-sample of transcripts was considered an acceptable measure of coding validity for the overall sample, following generally applied criteria for this level of exploratory study (Neuendorf 2002).

\subsection{Online survey}

A survey questionnaire focused on all competencies identified from the scoping study was presented to conservation professionals via Qualtrics, an online software platform (Qualtrics, Provo, UT; version 57201), and focused on the competencies identified from the scoping study. The survey consisted of six sections to establish the respondent's background in conservation (1), their personal engagement in leadership qualities (2), their perceived importance of leadership qualities (3), how frequently they have witnessed certain leadership qualities (4), their perception of the role of leadership in conservation (5) and respondent demographics (6). Items were mostly five-point Likert scales, ranking exercises and closed ended items (Newing 2010a). Where appropriate, respondents were asked to explain their answers through open-ended items. The survey also included an open-ended request for general comments. 
After piloting the survey with six people deemed representative of likely respondents, small refinements were made to the wording of some items, including simplification of technical language to make it more accessible, particularly for participants for whom English was a second language. Some negative competencies and qualities were rephrased or reversed to avoid extreme responses (Van Vaerenbergh \& Thomas 2013). The final survey (Appendix 1) was distributed to 175 conservation professionals via email through the author's networks, with each recipient asked to forward the survey to at least two other colleagues to increase the response rate.

To analyse the online survey questionnaire, means $(\bar{x})$ with standard deviations $(\sigma)$ were calculated using the Likert statement responses, for both importance and most frequently witnessed leadership competencies.

\subsection{Ethics}

Survey participants were informed of the scope and intent of the research prior to consenting to participate. They could respond anonymously, with results reported collectively to avoid identifying participants or organisations. The confidentiality of responses was maintained with only the lead author having access to participant's identities. Approval of the research proposal was secured through the ethics assessment procedure of the Faculty of Natural Sciences, Imperial College London.

\section{Results}

\subsection{Participant's characteristics}

Participants in the interviews, focus group and online survey were all, or had been, professionals engaged in a range of different types of initiatives and presented a range of leadership experience. 
The online survey was completed by 130 participants, of whom 104 had a leadership role (Table 1). Just over half of the respondents were male (51.5\%), and the majority of the respondents were from the United Kingdom (44.6\%) or the United States (29.2\%), although there were respondents from 16 different countries in total. Over 65 different conservation initiatives were represented, the majority of which were non-governmental organisations (NGOs).

\subsection{The role of leadership}

Most participants felt that leadership is 'Essential' (63\%) or 'Very important' (28\%) for effective conservation. Almost all participants (99\%) agreed an effective leader can increase the effectiveness of a conservation initiative, whilst $97 \%$ felt any individual could demonstrate leadership. Although the focus group discussions targeted leadership competencies, participants also noted that leadership is not always linked solely to formal responsibilities, for example:

"I know leaders that do not have staff below [them] but they are still mastering their job and are rallying people behind them." Participant 3.

\subsection{Competencies and qualities of effective leaders}

Fifteen positive competencies and three negative qualities were identified from the focus group and interviews (Figure 1). We make a distinction between the most important, and the most witnessed, competencies presented by effective leaders, as the frequency at which a competency is observed does not necessarily reflect its significance for effective leadership.

Competencies identified as most important for effective leadership included 'building trust amongst followers', the ability to 'create a vision that is inspirational', and the ability to 'demonstrate the behaviours they expect to see in others'. However, in conservation leaders, these competencies are less commonly perceived than leaders displaying experience with technical skills. 


\subsubsection{Important competencies}

The most important competency amongst participants of the online questionnaire was perceived to be the ability to 'Rally the team based on trust not fear'. The role of trust was discussed by many of the interview and focus group participants:

“...you think I agree with you, let's do it your way, I have trust in you, and if it fails, you may blame that person but I don't think that detracts from them being a leader as such, because you can't expect things to always be successful"

'Creating an inspirational vision' was considered the second most important competency of effective leadership (Table 2):

"It's worked best when I have been able to articulate a clear vision, I've been able to bring other people along with me, and create the enabling environment to make things work and let them grow". Participant 4.

The joint third most important competencies were 'Demonstrate the behaviours they expect to see in others' and 'Enable others around them to act, succeed and grow'. 'Effective communication within the team' was considered the fourth most important competency:

"For me, it's a huge thing, communication. We're dealing with complex stuff, that's hard to communicate number one, so you have to have an ability to clearly communicate". Participant 5.

'Considerable experience in the sector' was considered to be the least important competency for effective leadership out of those mentioned in the study, and 'Conservation as a primary passion' was scored as the second least important. 


\subsubsection{Frequently witnessed competencies}

Despite being considered as some of the least important, the most frequently witnessed competencies amongst participants of the online questionnaire were having 'Conservation as a primary passion' and 'Demonstrate considerable experience within the sector' (Table 3):

"Leadership in conservation is no different to leadership in any other walk of life, and there are a lot of transferable skills. The only thing that is taken as a given is the passion for the environment - that makes a difference" Participant 1.

However, the competencies considered the most important ('Rally their team based on trust, not fear' and 'Create an inspirational vision'), were reported as third and fourth most frequent. Although recognised as an important competency, 'Effective communication within the team' was not frequently witnessed, being only the $13^{\text {th }}$ most frequently witnessed out of the 18 competencies and qualities (Table 3). The least frequently witnessed competencies were 'Be self-aware of how they are as a leader' and 'Look to a mentor when support or guidance is needed'.

\subsubsection{Negative leadership qualities}

The three negative qualities ('Be as focused on achieving their own personal goals as the goals of the project, organisation or greater conservation action'; 'Be the sole decision maker'; 'Maintain a level of distance and detachment from the team'), were ranked as least important overall, and 'Maintain a level of distance and detachment from the team' and 'Be a sole decision maker' were also identified as the qualities that most compromise leadership (Table 2):

"It's that thing of feeling a level of control, of knowing if you're a member of a team, you have some control and you're not just at the whim of somebody's random decision making, actually you're brought into a strategy, and you can see the end goal." Respondent 7. 
These qualities were not witnessed particularly frequently by participants as being (Table 3 ), but they were witnessed more frequently than several competencies considered to be effective, including 'Ensure effective communication within the team', Be self-aware of how they are as a leader' and 'Looked to a mentor when support or guidance is needed'.

\subsection{Training leaders}

Most participants (89\%) agreed leaders should receive leadership training, although $67 \%$ of participants recognised that experience was equally important in developing leadership competencies:

"...having a go might bring leaders forward, so you build confidence and trust in people, and then they can show what they have to offer". Focus Group Participant.

\section{Discussion}

Effective leadership is fundamental to achieving organisational goals across sectors as diverse as business, education, healthcare and the military (Schriescheim \& Neider 1996; Nettles \& Herrington 2007; Curtis et al. 2011).Similarly, our study shows recognition of the importance of effective leadership clearly exists amongst conservation professionals. Although not directly covered by the study objectives, it became apparent that leaders are viewed not only as those in managerial positions, but that leadership can also be demonstrated by any member of an initiative.

An understanding of the competencies and qualities of effective leaders, what compromises effective leadership, and the systems in which leaders and their teams function well is a prerequisite for identifying, training and evaluating leaders within conservation. This understanding allows leaders' performance to be strategically and systematically developed, ensuring effective leadership is not left to chance. However, leadership is little researched within conservation (Bruyere 2015). This is the first study (the authors are aware of) identifying competencies deemed essential by both 
those being led, and by leaders themselves. Previous studies have used indirect measures, for example, expert opinion (Black et al. 2011), job advertisements (Blickley et al. 2013), or have focused on leaders alone (Dietz et al. 2004). There appears to be a growing consensus on what constitutes effective leadership, and the findings of this study are aligned with that. Further research into leaders and their followers, and the organisational contexts in which they operate is required (Bass \& Avolio 1993; Bennis 1999; Kouzes \& Posner 2006).

\subsection{How do we develop effective leaders?}

A distinction can be made between knowledge, skills, attitudes and behaviours, all of which combine to form leadership competencies. Disciplinary and contextual knowledge is also fundamentally important (Giesecke and McNeil 1999). An awareness of each of these elements by individuals, teams and initiatives, combined with strategically targeted education and training, is a prerequisite for developing effective leaders and leadership. Many important competencies reflect how leadership is enacted and can be developed through training and education.

\subsubsection{Interpersonal leadership skills}

In line with leadership literature from other sectors (Azim et al. 2010; Awan et al. 2015), competencies related to establishing and building personal relationships were considered most important for conservation.

The ability to build trust between individuals was considered the most important leadership competency in this study. Trust plays a key role in many of the common competencies previously identified by conservation leadership studies, including promoting collaboration amongst stakeholders, motivation of followers, and developing networks and relationships (Ardoin et al. 2015). Trust develops through strong interpersonal skills, and promotes strong team culture, leading to higher performing teams (Burke et al. 2007; Cheruvelil et al. 2014). It has, however, received little 
practical acknowledgement in ensuring effective leadership in conservation (but see Catalano et al. 2018), and leaders should have increased awareness of the importance of building trust amongst their followers, to ensure many other leadership qualities can be successfully portrayed.

A strong vision ('Create an inspirational vision') is deemed one of the most important elements of an effective organisation in the private sector (Bass \& Avolio 1993) and was identified as the second most important competency within the conservation context. The concept of a vision has repeatedly been highlighted in existing conservation literature (Black et al. 2011; Mattson et al. 2011; Bruyere 2015; Straka et al. 2018). Beyond academic literature, the Open Standards (CMP 2013) and Species Conservation Planning Sub-Committee guidelines (IUCN 2017) also both promote use of inspiring visions. Organisations investing in leadership development should therefore ensure training covers techniques for developing an inspirational vision. Post-activity debriefs (McGreevy \& Otten 2007) within teams are also essential, as they ultimately interpret a vision.

'Be self-aware of how they are as a leader' and 'Looking to a mentor for support or guidance' reflect personal and interpersonal insight, and were the most infrequently witnessed competencies. However, they are recognised as crucial beyond conservation, and can be harnessed, even without specific training (Baron \& Parent 2015), but this requires individuals who possess these qualities, to be identified and recruited. Recruitment in other sectors commonly involves scientifically assessing candidates for preferred competencies (Tett et al. 1991; Wilsher 2015). Conservation organisations should consider these techniques for future recruitment activities.

Passion and experience were not specifically recognised as leadership competencies, but were most commonly witnessed within leaders. 'Passion for nature' is a common reason why people work in conservation (Lele 2011); that it was frequently witnessed in conservation leaders is unsurprising. Passion is not developed through training, but can be grown through both experiences with nature 
(Curtin \& Kragh 2014) and positive team environments (Schwartz 2006). Previous literature has highlighted the value of knowledge in leadership (Black and Copsey 2014a; Sjölander-Lindqvist et al. 2015). Engaging leaders through on-the-ground activities may reinvigorate their passion for conservation, promoting a sense of purpose for an initiative, rather than a personal agenda (Black \& Copsey 2014b; Black 2015b). Striking an appropriate balance between passion, experience and interpersonal skills in leadership training will be essential as conservation increasingly shifts towards engaging organisational psychology and business approaches (e.g., Knight et al. 2011; Bennett et al. 2017).

\subsubsection{Poor Leadership}

Poor leadership was perceived as uncommon. Regardless, leaders and followers should remain vigilant to its implications, which may impact individuals, teams and initiatives through lower work/life satisfaction, increased emotional exhaustion (Tepper 2000) and reduced learning from failures (Catalano et al. 2018).

Poor leadership may be a consequence of high stress levels or being overworked, as leaders can 'burnout' faster than followers (Byron et al. 2001; Densten 2005; Bonar 2007). Accordingly, leadership should be researched not only in the context of success, but also failure. Our study did not identify these impacts of poor leadership, but there were three negative qualities that were explicitly noted (Figure 2): 'Being the sole decision maker', 'Maintain a level of distance and detachment from the team', and 'Be as focused on achieving their own personal goals as the goals of the project, organisation or greater conservation'. All three qualities are counteractive to important leadership qualities previously identified within the conservation literature. 'Being the sole decision maker' counteracts empowerment in relation to decision-makers (Cannon et al. 1996; SjölanderLindqvist et al. 2015), 'Maintain a level of distance and detachment from the team' could be detrimental to building relationships, team culture and hands-on leadership (Dietz et al. 2004; Black 
et al 2011; Bruyere 2015) and 'Be as focused on achieving their own personal goals as the goals of the project, organisation or greater conservation' may prevent a leader from having a sense of the bigger picture (Black et al 2011; Black and Copsey 2014a). More research is required to identify and understand negative impacts to both leaders and followers as individuals, teams, organisations and initiatives, inclusive of the costs and benefits of leadership. Once understood, training to address these phenomena should follow.

\subsection{Leadership within different contexts}

There is no single 'perfect' leader type, as effective leaders display various leadership styles. This is potentially of particular relevance in conservation, a highly diverse sector where individuals and teams may work on vastly different activities. Leadership competencies, and hence individuals, may be best matched to specific contexts.

In addition, it should be noted that the participants of the online survey were predominantly from the United Kingdom and the United States. The dominance of responses from these two countries is a limitation of the study, as it is recognised that what leaders do is influenced in part by their culture (Dickson et al. 2012; Straka et al. 2018). However, given the international nature of many conservation initiatives, certain leadership competencies may well be relevant across geographic boundaries, but these should be developed alongside cultural sensitivity and should adopt culturally relevant engagement (Mattson et al. 2011; Sutton 2015; Straka et al. 2018). Therefore, there is a need to explore leadership competencies in greater detail, to establish which are globally and more locally relevant.

\subsection{Training and education in 'technical' versus 'interpersonal' competencies}

The current focus on technical competencies by conservation organisations when recruiting new staff (Blickley et al. 2013) is difficult to explain, but our findings suggest a poor understanding of the 
relevative importance of leadership competencies. This is also suggested by our finding that several practices common to strong leaders in other sectors, including conducting debriefs (Catalano et al. 2018) and providing feedback (McCallum and O'Connell, 2009), went unreported by conservation professionals. It may be that these were considered implicit within other competencies, but our findings did not reveal if this was the case. This suggests that gaps remain in the awareness of bestpractices from other sectors that could offer pathways to increasingly effective leadership in the conservation sector. The belief that conservation professionals have an understanding of the qualities and competencies of effective leaders simply because they have been trained in, and have experience with, leadership seems flawed. Conservation has a poor record in training future professionals in interpersonal leadership skills (Golfomitsou 2015), despite wide recognition of their importance (Pant and Baroudi 2008; Marques 2013). Training in leadership by experts from other sectors seems prudent.

In this study, perceptions of 'Experience in the sector' implied technical skills, but these were not identified as highly important, despite being commonly witnessed. Jacobson and Duff (1998) argued that focusing on technical ability in conservation produces "idiot savants" - people with strong technical skills capable of generating information for supporting conservation activities (e.g., statisticians, modellers and geographic information scientists) but largely unskilled in the human and social competencies essential for implementing effective conservation initiatives. This present study suggests the same bias amongst current conservation leaders, leaving the true value of interpersonal skills largely unrecognised and unharnessed. Textbooks and degree courses focused upon traditional conservation biology perpetuate this blind spot, implicitly promoting the erroneous notion that interpersonal competencies are comparatively unimportant and/or are innate within individuals. This well-intentioned, but flawed, perspective directly limits the effectiveness of current and future conservation initiatives. 
Leadership should be made a core component of conservation degrees. Training students and earlycareer conservation professionals in interpersonal competencies, rather than just analytic and technical skills, will likely produce more effective leaders in the future (Newing 2010b). To secure competent educators and trainers, conservation organisations and universities must recruit beyond the scope of traditional conservation biology to include applied disciplines where leadership philosophies and techniques address personal reflection, communication, building collaborations and visioning (Dietz et al. 2004; Black et al. 2011). Such carefully targeted recruitment will better ensure conservation biologists are not training future conservation professionals in disciplines in which they are not formally qualified and have little experience. This will more effectively avoid the poor interdisciplinary research practices currently so prevalent in conservation (Jacobson \& McDuff 1998; Raymond \& Knight 2013; Sutherland et al. 2018).

Research into interpersonal leadership competencies probably lies beyond the expertise of conservation organisations at present, potentially creating reluctance to invest in such matters (Forbes 2011), maintaining the narrow focus on ecology at the expense of the social sciences (Raymond \& Knight 2013) and professional practice (Manolis et al. 2009). Learning from sectors with well-established understandings of leadership and interpersonal competency development could reduce the costs, and accelerate development of effective conservation leaders.

\subsection{How do we re-orientate leadership training?}

Conservation activities typically seek solutions to 'wicked' problems (Rittel \& Webber 1973), where multiple stakeholders with divergent values engage within complex and dynamic systems to achieve the 'common good'. Leaders therefore face significant challenges, as uncertainty is high and solutions are elusive and invariably context-specific, requiring long-term active management and integration of a diverse range of expertise and practice. 
Training in leadership should therefore adopt a problem-focused holistic approach that integrates a suite of carefully targeted complementary topics from across multiple disciplines and conducted across institutional scales for individuals, teams, organisations and initiatives. Conservation organisations and universities should commit to cooperatively develop curricula drawn from sectors aiming to drive transformations in complex systems, including evaluation, development, organisational management, systems thinking and the policy sciences (Knight et al. 2019). Approaches such as 'soft systems' methodology (Checkland 2000) could be particularly useful, focusing as it does more on interpersonal skills than on technical knowledge, as a means of tackling complex situations in an action-orientated way (Checkland \& Poulter 2006; Cundill et al. 2012). Embracing the philosophies, theories, methodologies and tools required to transform our collective approach to solving conservation problems will require humility from conservation professionals, demanding we acknowledge that, as professionals in a young sector, we may not recognise and can often lack, the expertise we require (Knight et al. 2019). Displaying the courage to unflinchingly embrace this fundamental shift in approach to leadership could form the basis of a new era of effectiveness in conservation (Meine \& Knight 1999).

\section{Acknowledgements}

We thank all study participants for their time and input. In addition, we thank the three anonymous reviewers whose comments and suggestions helped improve the manuscript.

\section{Conflict of Interest Statement}

The authors have no competing interests to declare. 


\section{Role of the funding source}

This research did not receive any specific grant from funding agencies in the public, commercial, or not-for-profit sectors.

\section{$\underline{\text { References }}$}

Ardoin, N.M., Gould, R.K., Kelsey, E. and Fielding-Singh, P., 2015. Collaborative and transformational leadership in the environmental realm. Journal of Environmental Policy \& Planning, 17(3), 360-380.

Awan, M.H., Ahmed, K. and Zulqarnain, W. 2015. Impact of project manager's soft leadership skills on project success. Journal of Poverty, Investment and Development, 8, 27-46.

Azim, S., Gale, A., Lawlor-Wright, T., Kirkham, R., Khan, A. and Alam, M. 2010. The importance of soft skills in complex projects. International Journal of Managing Projects in Business, 3(3), 387401.

Baron, L. and Parent, É. 2015. Developing authentic leadership within a training context: Three phenomena supporting the individual development process. Journal of Leadership \& Organizational Studies, 22(1), 37-53.

Bass, B.M. 1985. Leadership and performance beyond expectations. Collier Macmillan.

Bass, B.M. and Avolio, B.J. 1993 Transformational leadership and organizational culture. Journal of Public Administration Quarterly, 17, 112-121.

Bengston, D.N. and Fan, D.P. 1999. An Innovative Method for Evaluating Strategic Goals in a Public Agency Conservation Leadership in the US Forest Service. Evaluation Review, 23(1), 77-100. doi: 10.1177/0193841X9902300104

Bennett, N.J., Roth, R., Klain, S.C., Chan, K., Clark, D.A., Cullman, G., Epstein, G., Nelson, M.P., Stedman, R., Teel, T.L. and Thomas, R.E. 2017. Mainstreaming the social sciences in conservation. Conservation Biology, 31(1), 56-66.

Bennis, W. 1999. The leadership advantage. Leader to Leader, 12, 18-23. 
Bersin by Deloitte. 2014. The corporate learning Factbook ${ }^{\circledast}$ 2014: Benchmarks, trends and analysis of the US training market (Bersin \& Associates Factbook Report).

Bianco, M., Koss, R., and Zischka, K. 2016. Empowering emerging leaders in marine conservation. Aquatic Conservation: Marine and Freshwater Ecosystems, 26(S2), 225-236. doi: 10.1002/aqc. 2650

Black, S.A. 2018. Leading Species recovery: Influencing Effective Conservation, in Species Conservation: lessons from islands (Eds J.A. Copsey, S.A. Black, J.J. Groombridge, C.G. Jones) Cambridge University Press, UK.

Black, S.A. 2015a. Qualities of effective leadership in higher education. Open Journal of Leadership, 4(2), 54-66.

Black, S.A. 2015b. A Clear Purpose is the Start Point for Conservation Leadership. Conservation Letters, 8(5), 383-384. doi:10.1111/conl.12203.

Black, S. A., and Copsey, J. A. 2014a. Does Deming's "System of Profound Knowledge" Apply to Leaders of Biodiversity Conservation? Open Journal of Leadership, 3, 53-65. doi: 10.4236/ojl.2014.32006

Black, S.A. and Copsey, J.A. 2014b. Purpose, Process, Knowledge, and Dignity in Interdisciplinary Projects. Conservation Biology, 28(5), 1139-1141.

Black, S. A., Groombridge, J. J., and Jones, C. G. 2013. Using better management thinking to improve conservation effectiveness. ISRN Biodiversity. doi: 10.1155/2013/784701

Black, S.A., Groombridge, J.J. and Jones, C.G. 2011. Leadership and conservation effectiveness: finding a better way to lead. Conservation Letters, 4(5), 329-339.

Blickley, J.L., Deiner, K., Garbach, K., Lacher, I., Meek, M.H., Porensky, L.M., Wilkerson, M.L., Winford, E.M. and Schwartz, M.W. 2013. Graduate student's guide to necessary skills for non-academic conservation careers. Conservation Biology, 27(1), 24-34. 
Bodin, O. and Crona, B. 2008. Management of natural resources at the community level: Exploring the role of social capital and leadership in a rural fishing community. World Development 36(12), 2763-2779.

Bonar, S.A. 2007. The Conservation Professional's Guide to Working with People. Island Press, Washington

Bruyere, B.L. 2015. Giving direction and clarity to conservation leadership. Conservation Letters, 8(5), 378-382.

Burke, C. S., Sims, D. E., Lazzara, E. H., and Salas, E. 2007. Trust in leadership: A multi-level review and integration. The Leadership Quarterly, 18(6), 606-632

Byron, I., Curtis, A. and Lockwood, M. 2001. Exploring burnout in Australia's Landcare program: a case study in the Shepparton region. Society \&Natural Resources, 14(10), 901-910.

Cannon, J. R., Dietz, J. M., and Dietz, L. A. 1996. Training conservation biologists in human interaction skills. Conservation Biology, 10(4), 1277-1282. doi: 10.1046/j.1523-1739.1996.10041277.x

Case, P., Evans, L. S., Fabinyi, M., Cohen, P. J., Hicks, C. C., Prideaux, M., and Mills, D. J. 2015. Rethinking environmental leadership: The social construction of leaders and leadership in discourses of ecological crisis, development, and conservation. Leadership, 11(4), 396-423. doi: $10.1177 / 1742715015577887$

Catalano, A.S., Redford, K., Margoluis, R. and Knight, A.T. 2018. Black swans, cognition and the power of learning from failure. Conservation Biology 32(3), 584-596.

Checkland, P. 2000. Soft systems methodology: a thirty year retrospective. Systems Research and Behavioral Science, 17(1), 11.

Checkland, P. and Poulter, J. 2006. Learning for Action: A Short Definitive Account of Soft Systems Methodology, and Its Use Practitioners, Teachers and Students, Chichester, UK: Wiley.

Cheruvelil, K.S., Soranno, P.A., Weathers, K.C., Hanson, P.C., Goring, S.J., Filstrup, C.T. and Read, E.K. 2014. Creating and maintaining high-performing collaborative research teams: the 
importance of diversity and interpersonal skills. Frontiers in Ecology and the Environment, 12(1), 31-38.

Clark, T.W. and Reading R.P. 1994. A professional perspective: improving problem solving, communication and effectiveness. 351-369 in T.W. Clark, R.P. Reading, A.L Clarke (eds). Endangered species recovery: finding the lessons, improving the process. Island Press, Washington, D.C.

CMP (Conservation Measures Partnership). 2013. Open Standards for the Practice of Conservation. Version 3.0. $\mathrm{Http}: / / \mathrm{cmp}-$ openstandards.org/wp-content/uploads/2017/06/CMP-OS-V3.0Final-minor-update-May-2107.pdf [accessed 13 July 2017].

Cundill, G., Cumming, G.S., Biggs, D. and Fabricius, C. 2012. Soft systems thinking and social learning for adaptive management. Conservation Biology, 26(1), 13-20.

Curtin, S. and Kragh, G. 2014. Wildlife tourism: Reconnecting people with nature. Human Dimensions of Wildlife, 19(6), 545-554.

Curtis, E.A., de Vries, J. and Sheerin, F.K. 2011. Developing leadership in nursing: exploring core factors. British Journal of Nursing, 20(5).

Densten, I.L. 2005. The relationship between visioning behaviours of leaders and follower burnout. British Journal of Management, 16(2), 105-118.

Dickson, M.W., Castaño, N., Magomaeva, A. and Den Hartog, D.N., 2012. Conceptualizing leadership across cultures. Journal of world business, 47(4), 483-492.

Dietz, J.M., Aviram, R., Bickford, S., Douthwaite, K., Goodstine, A., Izursa, J., Kavanaugh, S., MacCarthy, K., O'Herron, M. and Parker, K. 2004. Defining leadership in conservation: a view from the top. Conservation Biology, 18(1), 274-278.

Evans L.S., Hicks C.C., Cohen P.J., Case P., Prideaux M. and Mills, D.J. 2015. Understanding leadership in the environmental sciences. Ecology and Society, 20(1), pp. 599-616

Forbes, P. 2011. Transforming conservation for the 21st century. Conservation Biology, 25(2), 209211. 
Franken, M., Branson, C. and Penney, D. 2016. A theory-to-practice leadership learning arrangement in a university context. International Journal of Leadership in Education, 19(5), 1-15. Http://dx.doi.org/10.1080/13603124.2016.1247196 [accessed 15 October 2017]

Giesecke, J. and McNeil, B. 1999. Core competencies and the learning organization. Faculty Publications, UNL Libraries, p.60.

Golfomitsou, S. 2015. Educating future professionals in conservation science: The challenges of an interdisciplinary field. Studies in Conservation, 60(2), 39-47.

Gordon, J.C. and Berry, J.K. 2006. Environmental leadership equals essential leadership: redefining who leads and how. Yale University Press, New Haven, Connecticut, USA.

Gutiérrez, N. L., Hilborn, and Defeo, O. 2011. Leadership, social capital and incentives promote successful fisheries. Nature, 470(7334), 386-389. doi: 10.1038/nature09689

Haubold, E. M. 2012. Using adaptive leadership principles in collaborative conservation with stakeholders to tackle a wicked problem: Imperiled species management in Florida. Human Dimensions of Wildlife, 17(5), 344-356. doi: 10.1080/10871209.2012.709308

Heifetz, R. A. 1994. Leadership without easy answers. Belknap Press, Cambridge, Massachusetts. Imperial, M.T., Ospina, S., Johnston, E., O’Leary, R., Thomsen, J., Williams, P., and Johnson, S. 2016. Understanding leadership in a world of shared problems: advancing network governance in large landscape conservation. Front Ecol Environ. 14(3): 126-134, doi:10.1002/fee.1248 IUCN - SSC Species Conservation Planning Sub-Committee. (2017). Guidelines for Species Conservation Planning. Version 1.0. Gland, Switzerland: IUCN. xiv + 114 pp.

Jacobson, S.K. and Duff, M.D. 1998. Training idiot savants: the lack of human dimensions in conservation biology. Conservation Biology, 12(2), 263-267.

Knight, A.T. 2006. Failing but learning: writing the wrongs after Redford and Taber. Conservation Biology, 20(4), pp.1312-1314.

Knight, A.T., Cook, C.N., Redford, K.H., Biggs, D., Romero, C., Ortega-Argueta, A., Norman, C.D., Parsons, B., Reynolds, M., Eoyang, G. and Keene, M. 2019. Improving Conservation practice 
with principles and tools from system thinking and evaluation. Sustainability Science, 1-18. DOI is https://doi.org/10.1007/s11625-019-00676-x

Knight, A.T., S. Sarkar, R.J. Smith, N. Strange and K.A. Wilson. 2011. Engage the hodge-podge: management factors are essential when prioritising areas for restoration and conservation opportunity. Diversity and Distributions 17(6): 1234-1238.

Kouzes, J.M. and Posner, B.Z. 2006. The leadership challenge. John Wiley \& Sons, New York, USA. Lauber, T.B., Stedman, R.C., Decker, D.J. and Knuth, B.A. 2011. Linking knowledge to action in collaborative conservation. Conservation Biology, 25(6), 1186-1194.

Leithwood, K.A. and Hopkins, D. 2008. Seven strong claims about successful school leadership. School leadership and management, 28(1), 27-42.

Lele, S. 2011. Rereading the interdisciplinary mindscape: a response to Redford. Oryx, 45(3), 331332.

London, M. 1999. Principled leadership and business diplomacy: A practical, values-based direction for management development. Journal of Management Development, 18(2), 170-192.

Macura, B., Secco, L., Pisani, E., Pullin, A.S. and Reyes-Garcia, V. 2016. All that glitters is not gold: the effect of top-down participation on conservation knowledge, attitudes and institutional trust in a Central Indian tiger reserve. Regional Environmental Change, 16(1), 125.

Https://doi.org/10.1007/s10113-016-0978-3 [accessed 4 August 2017]

Manolis, J.C., Chan, K.M., Finkelstein, M.E., Stephens, S., Nelson, C.R., Grant, J.B. and Dombeck, M.P. 2009. Leadership: a new frontier in conservation science. Conservation Biology, 23(4), 879886.

Marques, J. 2013. Understanding the strength of gentleness: Soft-skilled leadership on the rise. Journal of Business Ethics, 116(1), 163-171.

Mattson, D. J., and S. G. Clark. 2011. Human dignity in concept and practice. Policy Sciences, 44, 303320. doi: 10.1007/s11077-010-9124-0 
McCallum, S. and O'Connell, D. 2009. Social capital and leadership development: Building stronger leadership through enhanced relational skills. Leadership \& Organization Development Journal, 30(2), 152-166.

McGreevy, J.M. and Otten, T.D. 2007. Briefing and debriefing in the operating room using fighter pilot crew resource management. Journal of the American College of Surgeons, 205, 169176.

Meine, C. and Knight, R.L. 1999. The Essential Aldo Leopold: Quotations and Commentaries. The University of Wisconsin Press, Madison.

Mumford, M.D., Zaccaro, S.J., Harding, F.D., Jacobs, T.O. and Fleishman, E.A. 2000. Leadership skills for a changing world: Solving complex social problems. The Leadership Quarterly, 11(1), 1135.

Nettles, S.M. and Herrington, C., 2007. Revisiting the importance of the direct effects of school leadership on student achievement: The implications for school improvement policy. Peabody Journal of Education, 82(4), 724-736.

Newing, H. 2010a. Conducting research in conservation: Social science methods and practice. Routledge, Milton Park, Oxfordshire, United Kingdom.

Newing, H. 2010b. Interdisciplinary training in environmental conservation: definitions, progress and future directions. Environmental Conservation, 37(4), 410-418.

Neuendorf, K.A. 2002. The content analysis guidebook. Sage Publications Inc., Thousand Oaks, CA.

Pant, I. and Baroudi, B. 2008. Project management education: The human skills imperative. International journal of project management, 26(2), 124-128.

Raymond, C.M. and Knight, A.T. 2013. Applying social research techniques to improve the effectiveness of conservation planning. Bioscience, 63(5), 320-321.

Redford, K.H. and Taber, A. 2000. Writing the wrongs: developing a safe-fail culture in conservation. Conservation Biology 14, 1567-1568. 
Reichert, T., Lambiase, J., Morgan, S., Carstarphen, M. and Zavoina, S. 1999. Cheesecake and beefcake: No matter how you slice it, sexual explicitness in advertising continues to increase. Journalism \& Mass Communication Quarterly 76(1), 7-20.

Rittel, H.W. J. and Webber, M.M. 1973. Dilemmas in a general theory of planning. Policy Sciences 4, 155-169

Schriesheim, C.A. and Neider, L.L. 1996. Path-goal leadership theory: The long and winding road. The Leadership Quarterly, 7(3), 317-321.

Schön, D. 1983. The reflective practitioner.

Senge, P. 1994. Building learning organizations. The training and development sourcebook, 379.

Sjölander-Lindqvist, A., Johansson, M., \& Sandström, C. 2015. Individual and collective responses to large carnivore management: the roles of trust, representation, knowledge spheres, communication and leadership. Wildlife Biology, 21(3), 175-185. doi: 10.2981/wlb.00065

Schwartz, M.W. 2006. How Conservation Scientists Can Help Develop Social Capital for Biodiversity. Conservation Biology, 20, 1550-1552. doi:10.1111/j.1523-1739.2006.00421.x

Straka, T.M., Bal, P. Corrgan, C., Di Fonzo, M.M.I. and Butt, N. 2018. Conservation leadership must account for cultural differences. Journal for Nature Conservation. https://doi.org/10.1016/j.jnc.2018.03.003

Sutherland, W.J., Dicks, L.V., Everard, M. and Geneletti, D. 2018. Qualitative methods for ecologists and conservation scientists. Methods in Ecology and Evolution, 9(1), pp.7-9.

Sutton, A.E., 2015. Leadership and management influences the outcome of wildlife reintroduction programs: findings from the Sea Eagle Recovery Project. PeerJ, 3, p.e1012.

Tepper, B.J. 2000. Consequences of abusive supervision. Academy of Management Journal, 43(2), 178-190.

Tett, R.P., Jackson, D.N. and Rothstein, M. 1991. Personality measures as predictors of job performance: a meta-analytic review. Personnel Psychology, 44(4), 703-742. 
Tversky, A. and Kahneman, D. 1986. Judgment under uncertainty: Heuristics and biases. Science 184, 38-55.

Van Vaerenbergh, Y. and Thomas, T.D. 2013. Response styles in survey research: A literature review of antecedents, consequences, and remedies. International Journal of Public Opinion Research 25(2), 195-217.

Westrum, R. (1994) An organizational perspective: designing recovery teams from the inside out. Pages 327-350 in Clark, T.W., Reading R.P., Clarke A.L, editor. Endangered species recovery: finding the lessons, improving the process Island Press, Washington, D.C.

Wilsher, S. 2015. Behavior profiling: implications for recruitment and team building. Strategic Direction, 31(9), 1-5. 


\section{Figures and Tables}

Table 1. Demographic statistics of 130 respondents to an online survey questionnaire investigating important and common leadership competencies. All respondents were conservation professionals.

\begin{tabular}{|c|c|c|c|}
\hline \multicolumn{4}{|c|}{ Demographics $(N=130)$} \\
\hline Gender & Percentage \% & Nationality & Percentage \% \\
\hline Male & 51.5 & United Kingdom & 44.6 \\
\hline Female & 47.7 & United States & 30.7 \\
\hline \multirow[t]{2}{*}{ Prefer not to say } & 0.8 & Oceania & 6.9 \\
\hline & & Africa & 4.6 \\
\hline \multicolumn{2}{|c|}{ Undergone leadership training } & Asia & 3.9 \\
\hline Yes & 63.8 & Europe (exc. Britain) & 3.8 \\
\hline \multirow[t]{2}{*}{ No } & 36.2 & South America & 1.6 \\
\hline & & Unknown & 3.1 \\
\hline \multicolumn{2}{|c|}{ Experience in conservation } & \multicolumn{2}{|l|}{ Leadership experience } \\
\hline 5 years or less & 11.2 & 5 years or less & 29.2 \\
\hline $6-10$ years & 14.6 & $6-10$ years & 20.0 \\
\hline $11-15$ years & 16.2 & $11-15$ years & 18.5 \\
\hline $16-20$ years & 16.2 & $16-20$ years & 12.3 \\
\hline 20 years + & 41.5 & 20 years + & 20.0 \\
\hline
\end{tabular}


Table 2. The importance of competencies in leaders as reported by respondents to an online questionnaire. Responses to a five-point Likert Scale ranged from 'not at all important' to 'extremely important'. Three negative qualities identified during the interviews and focus group were included (italicised), alongside the competencies considered to be important.

\begin{tabular}{|c|c|c|c|}
\hline & Leadership competencies & Mean $(\bar{x})$ & Standard deviation $(\sigma)$ \\
\hline 1. & Rally their team based on trust, not fear & 4.75 & 0.45 \\
\hline 2. & Create an inspirational vision & 4.69 & 0.49 \\
\hline 3. & Demonstrate the behaviours they expect to see in others & 4.60 & 0.58 \\
\hline 4. & Enable others around them to act, succeed and grow & 4.60 & 0.95 \\
\hline 5. & Ensure effective communication within the team & 4.59 & 0.96 \\
\hline 6. & $\begin{array}{l}\text { Connect with their followers by recognising contributions } \\
\text { and celebrating successes }\end{array}$ & 4.49 & 0.56 \\
\hline 7. & Encourage growth and innovation & 4.42 & 0.83 \\
\hline 8. & Be reliable and consistent in decision making & 4.31 & 0.86 \\
\hline 9. & Be aware of benefits of adapting to the needs of their team & 4.24 & 0.83 \\
\hline 10. & Be self-aware of how they are as a leader & 4.19 & 1.01 \\
\hline 11. & Be a mentor for others & 4.15 & 1.03 \\
\hline 12. & $\begin{array}{l}\text { Provide team members the opportunity to pursue the } \\
\text { actions they think will be effective }\end{array}$ & 4.12 & 0.8 \\
\hline 13. & Look to a mentor when support or guidance is needed & 4.03 & 1.01 \\
\hline 14. & Have conservation as a primary passion & 3.91 & 1.01 \\
\hline 15. & Demonstrate considerable experience within the sector & 3.53 & 0.96 \\
\hline 16. & $\begin{array}{l}\text { Be as focused on achieving their own personal goals as the } \\
\text { goals of the project, organisation or greater conservation } \\
\text { action }\end{array}$ & 2.60 & 1.31 \\
\hline 17. & Be the sole decision maker & 1.90 & 0.99 \\
\hline 18. & Maintain a level of distance and detachment from the team & 1.75 & 0.91 \\
\hline
\end{tabular}


Table 3. The competencies in leaders most frequently witnessed by respondents to the online survey. Responses to a five-point Likert scale ranged from 'Almost never' to 'Almost always'. Three negative qualities identified during the interviews and focus group were included (italicised), alongside the competencies considered to be important.

\begin{tabular}{|c|c|c|c|}
\hline & Leadership competencies & Mean $(\bar{x})$ & Standard deviation $(\sigma)$ \\
\hline 1. & Had conservation as a primary passion & 4.21 & 0.81 \\
\hline 2. & Demonstrated considerable experience within the sector & 3.95 & 0.83 \\
\hline 3. & Rallied their team based on trust, not fear & 3.61 & 0.87 \\
\hline 4. & Created an inspirational vision & 3.56 & 0.87 \\
\hline 5. & Encouraged growth and innovation & 3.39 & 0.81 \\
\hline 6. & Demonstrated the behaviours they expect to see in others & 3.38 & 0.76 \\
\hline 7. & $\begin{array}{l}\text { Connected with their followers by recognising contributions } \\
\text { and celebrating successes }\end{array}$ & 3.35 & 0.83 \\
\hline 8. & Enabled others around them to act, succeed and grow & 3.28 & 0.84 \\
\hline 9. & $\begin{array}{l}\text { Provide team members the opportunity to pursue the actions } \\
\text { they think will be effective }\end{array}$ & 3.26 & 0.94 \\
\hline 10. & Been reliable and consistent in decision making & 3.17 & 0.89 \\
\hline 11. & $\begin{array}{l}\text { Been as focused on achieving their own personal goals as the } \\
\text { goals of the project, organisation or greater conservation action }\end{array}$ & 3.14 & 1.09 \\
\hline 12. & Been the sole decision maker & 3.13 & 0.96 \\
\hline 13. & Ensured effective communication within the team & 3.12 & 0.90 \\
\hline 14. & Been a mentor for others & 3.09 & 0.91 \\
\hline 15. & Been aware of benefits of adapting to the needs of their team & 3.05 & 0.83 \\
\hline 16. & Maintained a level of distance and detachment from the team & 3.01 & 0.89 \\
\hline 17. & Been self-aware of how they are as a leader & 2.66 & 0.91 \\
\hline 18. & Looked to a mentor when support or guidance is needed & 2.81 & 0.98 \\
\hline
\end{tabular}




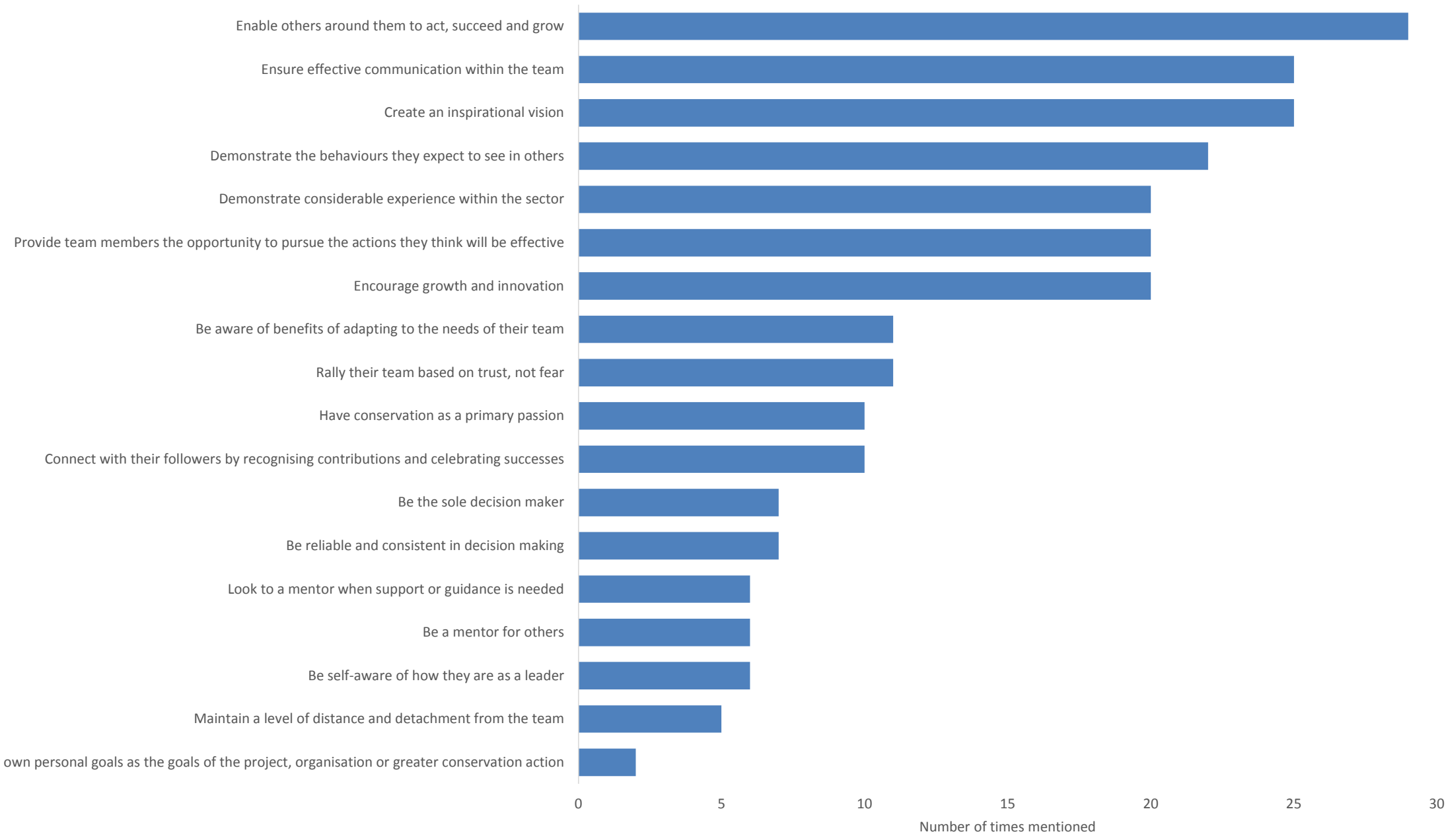

Figure 1: Leadership competencies perceived by conservation professionals through interviews and a focus group. Competencies of effective leadership were primarily captured, but key negative qualities were also documented. 


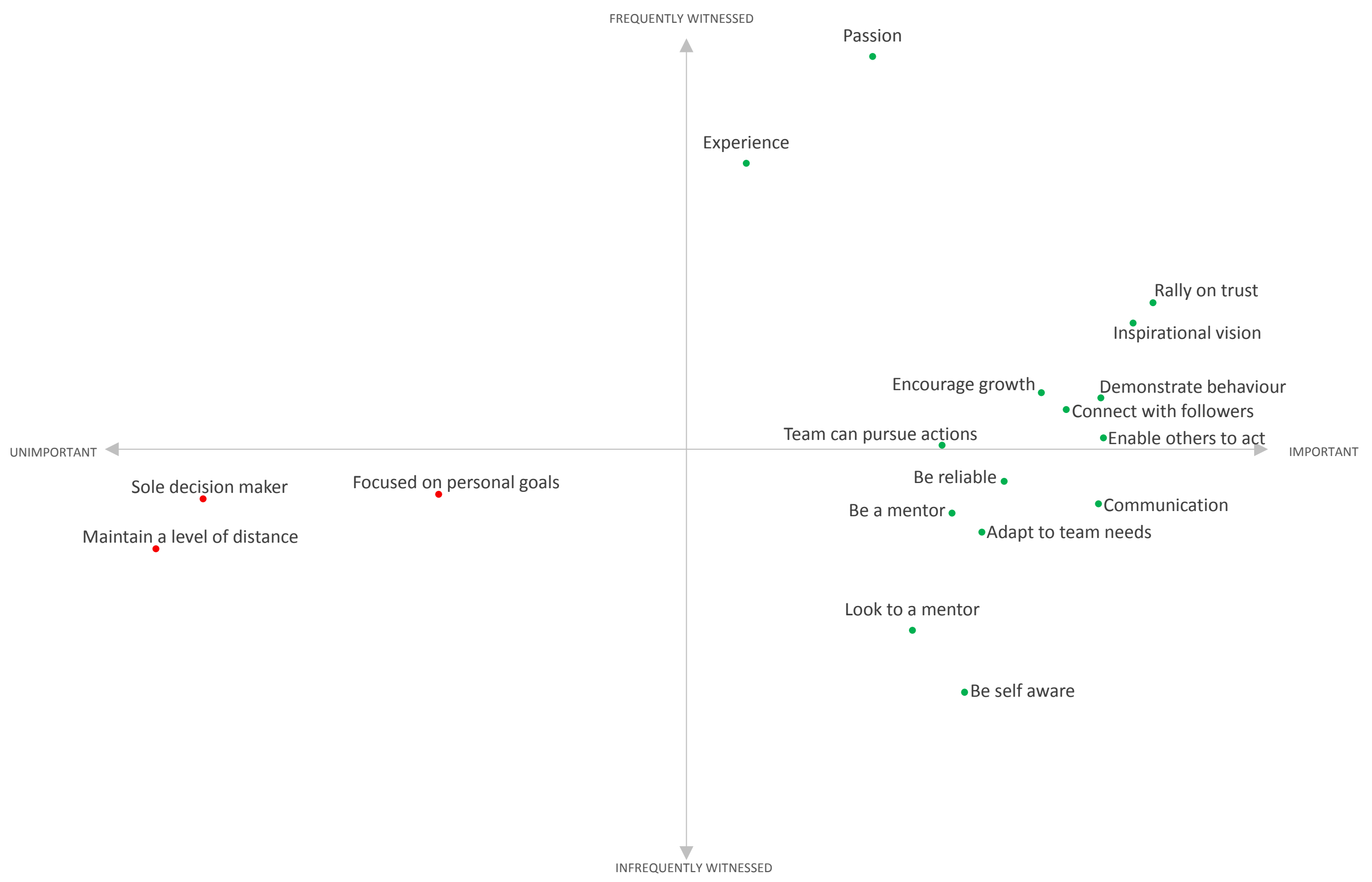

Figure 2. Leadership competencies and qualities displayed for importance and how frequently they were witnessed in leaders. Positive competencies are presented in green, and negative qualities are presented in red. The full name of each competency and quality is listed in Table 2 and 3. 